\title{
Perceptions of Obese African American Women Regarding Altering Traditional Soul Food Preparation
}

\author{
Patricia A. Young \\ Walden University
}

\begin{abstract}
The obesity epidemic continues to be a major concern in the United States. The World Health Organization reported that 1.4 billion adults were either obese or overweight African American (AA) women have the highest incidence of obesity worldwide. A qualitative descriptive study was used to explore the perceptions of obese AA women about altering how they prepare soul food to make it healthier. The empowerment model and the health belief model were used to frame this study. Data were collected using a nonprobability purposeful sampling strategy. The sample for this study consisted of four focus groups with six to seven obese AA women ages 21-90 who prepared and consumed high-calorie soul foods and had a body mass index $\geq 30$. Focus group transcripts were analyzed using a constant comparative analysis. It was found that obese AA women were willing to alter their traditional soul food preparation only if it tastes good, recipes are available, it is cost effective, and it produces minimum food waste. Barriers that could limit participation in an intervention as well as recommendations for designing interventions are discussed.
\end{abstract}

Keywords: healthy eating, traditional soul food, obesity, empowerment model, health belief model, African American women

\section{Introduction}

Globally, 1.4 billion adults are considered obese or overweight (American Medical Association, 2013). The U.S. Department of Health and Human Services, Office of Minority Health (2017) reported that African American (AA) women have the highest rate of obesity than any other ethnic group in the United States. Specifically, it was reported that four out of five AA women are obese or overweight, and obesity rates are continually increasing among this population (Zylke \& Bauchner, 2016). Despite the many studies conducted on obesity over the past 2 decades, the obesity rate continues to rise among AAs, contributing to the risk of hypertension, coronary heart disease, diabetes, depression, and cancer (Zylk \& Bauchner, 2016).

AA women generally prepare and consume high-calorie foods that contribute to obesity (Broady \& Meeks, 2015; Jensen Wallach, 2014; Wilson \& Sato, 2014). The obesity rate is steadily increasing in the United States despite the medical problems that can result from eating high-calorie foods, and previous research suggests that AA women are not willing to give up their cooking tradition because they fear that they would be giving up their heritage (Belle, 2009; James, Pobee, Oxjdine, Brown, \& Joshi, 2012; Lopez et al., 2014, Reed et al., 2016).

In the early $1600 \mathrm{~s}$, AA slaves brought their style of cooking to America, which became a part of the AA culture and heritage (Petrick, 2011; Spooner, 2015). The AA culture has changed over the years, and today AAs prepare foods that are high in calories, salt, sugars, and fats. These foods are referred

This article is based on data from the author's doctoral dissertation at Walden University, Minneapolis, MN. Faculty committee on the project were Drs. Lee Stadtlander, Matthew Howren, and Andrea Goldstein. 
to as soul food (Bratanova, Loughnan, Klein, Claassen, \& Wood, 2016; Hall, 2016). It became a tradition for AA families to come together on special occasions to prepare and consume soul food (Belle, 2009). Today, some AAs have changed the way they prepare traditional soul food to make it healthier, such as by substituting smoked turkey instead of animal fats; baking, grilling, and broiling meats instead of frying; including more fresh fruits and vegetables; and using herbs and spices to season their food (Belle, 2009; James et al., 2012; Reed et al., 2016). Therefore, the purpose of this study was to gather the perceptions of obese AA women regarding factors or elements that would help researchers to develop effective interventions on altering the preparation and consumption of traditional soul food.

Past studies have focused on developing and implementing interventions, programs, and workshops that include components of obesity, weight loss, and weight maintenance (Amirrood, Taghdisi, Shidfar, \& Gohari, 2014). The research involved studies on nutrition, healthy eating, healthy lifestyles, and nutrition education including cooking lessons (Geller, Dube, Cruz, Stevens, \& Bench, 2015; Jurkowski, Lawson, Green Mills, Wilner, \& Davison, 2014; Lavalle et al., 2016). There were also studies on physical activity and health behaviors, spiritual/scripture support, and improving dietary intake to impact body composition and bodily functions (Bronikowski et al., 2016; Davison, Jurkowski, Li, Kranz, \& Lawson, 2013; Huang et al., 2014). Other studies included obesity and diabetes care, obesity and breast health, general health and safety education, and osteoporosis education (Rashid et al., 2017; Sheean et al., 2016). Additionally, studies were conducted on local restaurant and fitness guide, fitness diaries, and relapse prevention (Boh et al., 2016; Fukawa, 2016; Lavalle et al., 2016; Polsky, Moineddin, Dunn, Glazier, \& Booth, 2016; Rodgers et al., 2016; Yates et al., 2015). Finally, Rahmati-Najarkolaei, Tavafian, Fesharaki, and Jafari (2015), conducted community-based participatory studies that included an intervention to prepare church members to eat more fruits and vegetables, exercise at least $30 \mathrm{~min}$ a day, and to try new recipes to ensure healthier meals for their families.

AA women generally prepare and consume high-calorie soul foods as a means of providing comfort, hence the name comfort foods (Waters, Diggins, Woods-Giscombe, \& Waters, 2015). Eating highcalorie comfort foods has been directly related to obesity among this population (Cho, Jae, Choo, \& Choo, 2014; Waters et al., 2015). James et al. (2012) posited that AA women could reduce obesity if they would consistently prepare and consume soul foods that were cooked using healthy ingredients.

To understand the perceptions of obese AA women regarding altering traditional soul food preparation to reduce obesity, as well as the factors that obese AA women perceive would be helpful to maintain healthier new eating behaviors, data were collected from obese AA women using focus group interviews. A focus group design allowed participants an opportunity to share new ideas, debate different perspectives, and create new concepts (Liamputtong, 2011; Patton, 1990).

Participants in this study were able to identify the perceptions of obese AA women regarding altering traditional soul food preparations to reduce obesity. The participants were able to identify factors that AA women perceive would be helpful to maintain healthier new eating behaviors. And finally, participants were able to identify what barriers could limit AA women's participation in an intervention program designed to help obese AA women develop healthier eating behaviors. The results from focus group interviews present the perceptions and barriers that obese AA women have regarding altering the way they prepare and consume high-calorie soul food so that interventions that focus on these perceptions and barriers can be developed. 


\section{Method}

\section{Participants}

Consent was granted from the owner of the research site to conduct focus group interviews. A nonprobability purposeful sampling strategy was used to the select the sample. Upon approval from Walden University's Institutional Review Board (Approval Number 11-06-17-0069640), participants were recruited from sites on the Southside of Chicago, Illinois, that provided services to predominately AA women who were recruited in a private and sensitive manner.

\section{Procedure}

The prospective participants were selected from outside of the recruitment site. Flyers were handed out to individuals as they left the specified site. Additional flyers were placed at the location where prospective participants were recruited. Participants were also chosen from two AA churches on the Southside of Chicago. Interested individuals were briefed in the Sunday school classroom on their role as a participant, their rights, and the consent process. Interested participants were given a consent form to read and a self-addressed, stamped envelope to return the consent form.

As signed consent forms were received in the mail, the prospective participants were contacted by phone to complete a prescreening eligibility questionnaire for participation in focus group interviews. The sample size for each focus group interview consisted of four groups of six to seven obese AA women $(n=25)$ who prepare and consume high-calorie soul foods and have a body mass index $\geq 30$. There were four focus group sessions, each lasting 94 to $113 \mathrm{~min}$. To get participants relaxed, at the start of each focus group interview, three warm-up questions were asked. A focus group protocol was used to guide each focus group session. Nine open-ended questions were asked to provide rich data to design program interventions to help obese AA women develop healthier eating behaviors.

\section{Results}

Each focus group session was conducted at a centralized location on the Southside of Chicago. After the time slot for the first focus group was filled, the first focus group interview was conducted. All focus group interview sessions were recorded using a tape recorder and an iPad (Model \# MD042LL/A, Apple Inc., Cupertino, CA). Demographics of participants are listed in Table 1.

Session 1 consisted of seven participants ranging in age from 22 to 74 years of age. Session 2 consisted of six participants ranging from 56 to 68 years of age. Session 3 consisted of six participants ranging from 29 to 59 years of age. Session 4 consisted of six participants ranging from 18 to 90 years old. 
Table 1. Demographics of Participants

\begin{tabular}{lcc}
\hline Demographic & $\boldsymbol{n}$ & $\mathbf{\%}$ \\
\hline Ages & 3 & \\
Young adults (18-35 y) & 6 & 24 \\
Middle-aged adults (36-55 y) & 10 & 40 \\
Older adults (56-65 y) & 6 & 24 \\
Senior citizens (>65 y) & & \\
Body mass index & 14 & 56 \\
30-35 & 11 & 44 \\
>35 & 4 & \\
Prepared traditional soul food & 2 & 8 \\
Daily & 4 & 16 \\
$4-5$ d/wk & 11 & 44 \\
2-3 d/wk & 4 & 16 \\
Only on weekends & & \\
Once a month & 4 & 16 \\
Consumed traditional soul food & 2 & 8 \\
Daily & 8 & 32 \\
$4-5$ d/wk & 7 & 28 \\
2-3 d/wk & 4 & 16 \\
Only on weekends & & \\
Once a month & & \\
\hline
\end{tabular}

The data analysis process included reading through the transcripts, identifying emerging themes and patterns, assigning codes to the data, arranging the data for analysis, and writing up the findings in a final report. Data were reduced by using qualitative content analysis. Common themes and patterns were identified, codes and key concepts were created from the data, and subthemes and patterns were identified. A thorough analysis was initiated using the computer software, NVivo 11 for Windows, which provided relevant themes for analysis through common word recognition. NVivo 11 was also used to identify themes in the raw data, as well as information under the different themes that emerged from the raw data. NVivo 11 helped to organize, store, and code the data more effectively to achieve an in-depth understanding of what AA women think about altering the preparation and consumption of traditional soul food.

\section{Research Questions}

Research Question 1: What are the perceptions of obese AA women regarding altering traditional soul food preparation?

The themes that emerged from the analysis to answer Research Question 1 were taste, family values, and consequences. The taste was important to participants when they considered altering soul food preparation. All participants loved the way traditional soul food tastes; therefore, it is important to consider the taste of any altered soul food preparation to create willingness for AA women to change the way they prepare traditional soul food. Participant 5 said, "I'm just saying healthy soul food doesn't taste the same. Now you can accept what you get from the final results if you chose to, but it will not taste the same."

The second theme was family values. Soul food and family seemed to go hand in hand. Participants felt that high-calorie soul food was a part of their heritage and it placed joy in their hearts. 
Participant 4 stated, "during holidays, you want to cook your best dishes and they're [going to] fall back to soul food. It's something that the people look forward to; it puts a smile on your face."

There were two subthemes that emerged under consequences: improved health and reducing chronic illnesses. All of the participants expressed that traditional soul food was not healthy to eat; however, they felt that the positive aspects and the good taste outweighed the consequences of eating it. Participants in all four focus groups stated that if soul food could be prepared in a healthy manner and still tastes good, they would be willing to change the way they prepare it. Participant 24 said, "Down the road, when you get older, you get sick from eating unhealthy soul food."

Participants in all four focus group sessions agreed that eating high-calorie soul food causes unfavorable health conditions such as heart attacks and other problems such as high cholesterol, stroke, clogged arteries, hypertension, obesity, diabetes, and respiratory problems. Participants also agreed that eating healthy soul food would improve their health, which would lower the cost of health care. For these reasons, some participants stated that they would be willing to change the way they prepare soul food. All participants agreed that eating healthy soul food would increase one's quality of life and may reduce chronic illnesses.

Research Question 2: What factors do obese AA women perceive would be helpful to maintain healthier new eating behaviors for themselves and their families?

There were six factors (themes) that emerged from the analysis to answer Research Question 2: (a) good taste, (b) recipe availability, (c) low cost of healthy ingredients, (d) accessibility of ingredients, (e) learning how to substitute various herbs and spices, and (f) food waste. Taste was found to be the motivational factor for maintaining healthy eating behaviors.

One factor that the participants perceived would help to maintain healthier new eating behaviors for themselves and their family was that the new soul food tastes good. All participants in the four focus group sessions felt that healthy soul food would not be tasty because of their past experiences in trying to consume healthy soul food. The participants were adamant about the taste of soul food; it had to taste good before they would be willing to consume or prepare it.

The second factor that the participants perceived would help to maintain healthier new eating behaviors for themselves and their family was recipe availability. The only soul food recipes that the participants knew were those that were handed down through the generations. They had not heard of healthy soul food recipes.

The third factor that the participants perceived would help to maintain healthier new eating behaviors for themselves and their family was the low cost of healthy ingredients. Participant 20 said that "a lot of people can't cook healthy, because it cost so much." Then Participant 22 added that "they're on a fixed income."

The fourth factor that the participants perceived would help to maintain healthier new eating behaviors for themselves and their family was the accessibility of the ingredients needed to prepare healthy soul food. Participants in the focus groups stated that the availability of fresh vegetables, fruits, and herbs in the AA communities are scarce. Other participants talked about lack of transportation to and from fresh market places because these sites were usually located outside of the city. 
The fifth factor that the participants perceived would help to maintain healthier new eating behaviors for themselves and their family was learning how to substitute various herbs and spices. Some of the participants were knowledgeable about substituting herbs and spices for their soul food to make it healthier, and many of the participants expressed a desire to learn how to season foods. This was the case in all four focus group sessions.

The last factor that the participants perceived would help to maintain healthier new eating behaviors for themselves and their family was food waste. Participants discussed the possibility of having to throw food away because when they prepared it in a healthy manner, it was not tasty. Therefore, food waste was a major concern.

Research Question 3: What barriers could limit participation in an intervention designed to develop healthier eating habits for obese AA women?

The themes that emerged from the analysis to answer Research Question 3 were simple reasons why AA women would not attend an intervention, such as ignorance and laziness, transportation issues, lack of motivation, lack of education, and lack of time.

The first theme was ignorance and laziness. The participants felt that AA women who continue to consume traditional soul food would not attend cooking workshops to teach them how to prepare healthy soul food due to ignorance or laziness. Participant 20 added, "If you don't know better, you can't do better." In all four focus groups, it was made clear that AA women need to be knowledgeable about the importance of altering the way they prepare traditional soul food, as well as how to alter its preparation.

The second theme was transportation issues. The participants discussed how AA women have issues with transportation. Many of the participants rely on public transportation to move about the city. Some of the participants brought up the fact that transportation would be needed to attend cooking classes if offered. Participant 6 stated that "it's about economics ... it's like everyone does not have a car or live in a car, and everyone does not have public transportation." Participant 13 stated that "transportation is a problem for some folks."

The third theme was lack of motivation. The participants expressed that AA women must be motivated before they would change the way they prepare and consume traditional soul food. Participant 25 stated, "We have to have a frame of mind if we want to live longer ... we have to have motivation, drive, and willpower." Participants from all four focus groups suggested a support group or a social group was needed to address obesity.

The fourth theme was lack of education. The participants discussed how the lack of education would affect their decision to participate in an intervention to alter soul food preparation. The participants encouraged one another by stating, "You just have to find an option that is [going to] save your life; keep you healthy, and the only way to do that is through education." Participant 12 added a need to "educate the next generation and teach them to prepare soul food healthy."

The fifth theme was lack of time. Many of the participants stressed the fact that they did not have time to learn how to alter soul food preparation. Participants attempted to encourage one another to make time for themselves. For example, Participants 9 and 12 stated that AA women "need to make time for learning how to prepare healthy soul food.” 
The subthemes were no incentives and bad reviews. Some of the participants rallied around the idea that cooking interventions should provide attractive incentives. Other participants stated that if the healthy soul food tastes good, people will come and be receptive to change. All participants felt that the cooking classes should be free. Some participants suggested that cooking classes should include an inviting atmosphere, cleanliness, and safety. Others felt that food dishes should taste good and that the person who teaches the class should be polite, clean, and easy to work with. The participants from all four focus groups agreed that if people do not take anything away from the cooking lessons, they will not be successful at adopting new eating or cooking habits.

\section{Other Relevant Ideas From Participants}

Other relevant ideas illuminated during this study were that obese AA women should be open to alternatives that would benefit them. They should be open to receive information that may change their lives and the lives of their families. When AAs make an informed decision to do better, they will be open to learn and do the things (such as going to cooking classes) that create positive social change in their communities. With today's technology, information can reach the multitudes with a touch of a button or click on the mouse. When people are diagnosed with health conditions such as high blood pressure, Type II diabetes, obesity, and heart diseases, they need to be honest with themselves and learn ways to alleviate their problems. If AAs are not preparing or consuming healthy foods, then they should realize that their mortality and morbidity are at risk and it is time to change.

\section{Discussion}

This article addresses the problem of obesity among AA women as a result of consuming high-calorie soul food. Understanding the perceptions of obese AA women regarding altering traditional soul food preparation to reduce obesity and the factors that obese AA women perceived was found to be helpful to maintain healthier new eating behaviors. The information gathered from existing research, along with the results presented in this article, will be useful in designing an intervention that would teach obese AA women to practice healthy soul food preparation and motivate obese AA women to adopt and sustain healthy soul food preparation.

\section{Research Question 1}

Participants from each focus group indicated that taste was an important factor in determining whether they would consider altering the preparation of soul food. Taste was important to participants and preparing soul food was a part of their family traditions and values. This confirms what Belle (2009) stated in her study, that AA women will always prepare and consume traditional soul food because it tastes good and it is a part of the AA culture. The results of this study aligned with Belle's (2009) and Beagan and Chapman's (2012) study results showing that AA women would not stop preparing and consuming traditional soul food due to hereditary concerns. Specifically, Beagan and Chapman noted that AA women felt that their heritage would be lost if they gave up traditional soul food.

Participants from the focus groups discussed their experiences with their families when preparing and consuming soul food during holidays or special occasions. The participants regarded these events as family values to pass down from generation to generation. This is in line with the research from Broady and Meeks (2015) and Thompson (2015), which concluded that AA women pass down soul food recipes from generation to generation, which AA women prepare and consume regardless of 
socioeconomic status. For many of the participants, consuming soul food was only one part of the experience of family values; being together once or twice a year and family members sharing their recipes was part of the occasion. This study confirms Belle's (2009) study that AAs enjoy the flavor of traditional soul food, especially during gatherings with friends, family, and members of the community.

While many of the participants from each focus group were aware of the consequences of consuming traditional soul food and the chronic illnesses associated with consuming foods high in calories, fats, and sugars, participants appeared to associate their chronic illnesses such as hypertension, diabetes, and obesity as unrelated to eating traditional soul food. All participants felt that they were healthy and did not realize that a body mass index $\geq 30$ was overweight or obese. While most AA females during the 1950s were large, their appearance was viewed as positive, indicating that AA women who were obese cooked good soul food dishes (Chen, Williams, Hendrickson, \& Chen, 2012). According to Chen et al., obese AA women think that people with excess weight are healthy and small people are unhealthy. They also posited that obese AA women know that consuming highcalorie soul food is detrimental to their health, but if done in moderation, it is acceptable and not considered unhealthy.

\section{Research Question 2}

The themes that emerged from the analysis to answer Research Question 2 were factors for eating healthy such as good taste, recipe availability, low cost for healthy ingredients, accessibility of the ingredients, substitutions of herbs and spices, and food waste. The results of this study confirmed the findings from Jurkowski et al. (2014) and Lee and Lien (2015) that the main factor that influences obese AA women to continue to prepare and consume traditional soul food is the taste. Obese AA women love and desire the rich taste of traditional soul food.

There was no research found that addressed the availability of healthy soul food recipes, but according to the findings in the present study, if tasty recipes for healthy soul food were available, AA women would alter their recipes. This study found that obese AA women will always prepare and consume traditional soul food because it is inexpensive. Additionally, it was bought out in this study that healthy foods were more expensive than unhealthy alternatives and easily accessible. In this study, fresh fruits and vegetables and the ingredients used to prepare healthy soul food were higher in cost. This confirms Li, Robinson, Carter, and Gupta's (2015) study that, in many AA communities, fresh fruits and vegetables are hard to access or too expensive to purchase.

There was no previous research found that addressed substituting herbs and spices to replace unhealthy ingredients such as lard, shortening, sugars, salt, and fats. There were no previous studies that addressed issues of food waste. However, the participants in this study confirmed that if altering a soul food dish in a healthy manner resulted in the food tasting unsavory, it would be discarded, and no one could afford to waste food. Overall, participants viewed barriers to cooking using raw ingredients as time constraints, saving money, easy preparation, food choices, and fear of preparing the food inadequately.

\section{Research Question 3}

The themes that emerged from the analysis to answer Research Question 3 were the barriers for participation in an intervention such as ignorance and laziness, transportation issues, lack of motivation, education, and time, no incentives, and bad reviews. There was no previous research found on ignorance and laziness, lack of motivation, or bad reviews, but these factors were very 
prevalent in the present study. During the focus group sessions, I found that obese AA women were not knowledgeable about the negative effects of consuming traditional soul food. Participants stated that laziness was the reason why many AAs consume unhealthy foods, especially snacks. They felt that purchasing processed snacks and foods at a local grocery store or buying burgers from a fast food eatery were more convenient and cost effective than preparing snacks and foods using fresh fruits and vegetables.

In past research, interventions on healthy food consumption did not address incentives that would increase participation. In the previous research, many interventions were conducted on healthy food consumption, but none of them addressed incentives that would increase participation. However, Rodgers et al. (2016) used mobile technology (e.g., iPhone or other smartphone) to encourage healthy eating to reduce obesity. Although the results of their study were not favorable, Rodgers et al. acknowledged that using the technology was a creative way to enhance participation in healthy eating intervention, but more research needed to be done to increase adherence. As far as bad reviews are concerned, this study concluded that people would not attend interventions if the sites were unclean, unsafe, or the researcher and the staff were unpleasant.

The results of the present study also confirm research conducted by Jurkowski et al. (2014) and Lee and Lein (2015) that an environmental factor that hinders AA women from eating healthy is the lack of healthy foods within AA communities, as well as the cost of healthy foods. It was noted in the research that AA communities are more prone to having fewer grocery stores that provide a wide variety of fresh fruits and vegetables, whole grains, fresh fish and other seafood, and low-fat dairy products, and if healthier alternatives are available, they are considerably higher in cost and lower in quality (Bower et al., 2015; Broady \& Meeks, 2015; Cozier et al., 2014; Nederkoorn, 2014).

This study also confirms that the AA population needs education on substituting unhealthy ingredients with healthy alternatives, so they would understand the importance of changing the way they prepare and consume traditional soul food. Because obese AA women are going to continue to prepare and consume traditional soul food, then it may be advantageous for AA women to receive training on how to prepare traditional soul food in a healthy manner to reduce obesity and unfavorable health conditions. The results of this study confirm the information from Lavalle et al.'s (2016) study that obese AA women may need to learn how to cook in large quantities and freeze the products for later use. They also need instructions on how to prepare tasty soul food dishes in a healthy manner.

\section{Theoretical Frameworks}

Based on the findings from the literature, empowerment alone would not be sufficient to ensure a successful intervention; instead, there is a need to integrate both empowerment and health literacy in the intervention because one without the other would prove ineffective (Schulz, 2014; Schulz \& Nakamoto, 2013; Shu-Fang et al., 2016). According to Shu-Fang et al., obese AA women are not knowledgeable and do not have access to the resources that would be needed to create change without community support to alter the way they prepare and consume traditional soul food to reduce obesity. The empowerment model is designed to help individuals to make decisions about their health to enhance healthy behaviors, improve health status, and reduce health inequalities in their community. In this study, the empowerment model was effective in helping obese AA women to feel a sense of control, to have options to choose from, to have the ability to connect with others, and to have a sense of security. During all focus group sessions, there were ongoing discussions among the members who helped participants to increase their health literacy, thus empowering each other 
to want to do better. It was evident in each focus group session that participants began to think about their obesity and the direct effects of consuming traditional soul food. They openly expressed their health issues and the health problems other members of their families were dealing with. The discussions enhanced their understanding of the research problem and motivated them to want to make informed decisions about their health to improve their health and reduce chronic illnesses in their families.

Results from previous research that used the health belief model (HBM) found that participants believed that they were obese because of their culture and genetics and not because of the foods they ate (James et al., 2012). However, participants in the present study realized that if they lost weight, they would have a healthier life, eliminate health risks, and enhance their physical appearance. Additionally, participants in this study needed motivation, adequate information on dieting, and community support.

During the focus group sessions, participants made comments, talked about their experiences, and shared their beliefs and knowledge on obesity and their love for traditional soul food. Therefore, information collected from the focus groups will be used to design and develop interventions to address obesity as a result of consuming traditional soul food. The themes from the HBM may be used to construct a healthy soul food intervention. The HBM will shed light on why participants decided to alter the way they prepare and consume traditional soul food for better health (Becker, Maiman, Kirscht, Haefner, \& Drachman, 1977).

Past studies have found that the HBM was effective in predicting how individuals react to their perceptions; if individuals perceived negative consequences as a result of their actions, they would be willing to change their behaviors. Additionally, if participants resided in communities that promoted proactive health care, participants would be more likely to change unhealthy behaviors (Kim \& Zane, 2016; Rahmati-Najarkolaei et al., 2015). The findings from the present study suggest that for obese AA women to alter the way they prepare and consume traditional soul food, they must perceive that eating unhealthy soul food contributes to their mortality and decreases their quality of life (Glanz, Rimer, \& Viswanath, 2008).

During the focus group discussions, all participants perceived the benefits, barriers, and self-efficacy of preparing and consuming healthy soul food. Because these obese AA women perceived that eating the traditional soul food had a direct impact on their health, if they altered the way they prepared and consumed soul food, it would improve their health and reduce chronic illnesses. Additionally, participants realized that barriers would have to be removed to alter the way traditional soul food is prepared and that they must have accessibility to affordable foods that can be prepared in a healthier manner while maintaining its taste. Finally, participants believed in their ability to successfully alter their soul food preparation in a healthier manner, thus increasing their selfefficacy. They also expressed that they would need recipes and other resources to teach them how to alter their soul food preparation to ensure good taste.

\section{Limitations of the Study}

Limitations were addressed while conducting this study. The first limitation was that all participants did not have the same level of concern for eating healthy as others, which could introduce controversy among the participants. Initially, participants did not have the same level of concern regarding healthy eating behaviors as others; however, this did not cause controversy among the participants. Although participants shared different views concerning the preparation and 
consumption of traditional soul food, they expressed their thoughts openly so that barriers to altering the way obese AA women prepare and consume high-calorie soul food could be identified.

Another limitation of this study was that prospective participants needed to be recruited culturally, sensitively, and privately (Chang, Nitzke, Brown, Egan, Bendekgey, \& Buist, 2017; Sharp, Fitzgibbon, \& Schiffer, 2008). Sharp et al. conducted active recruitment of obese AA participants. Their recruitment process was conducted by the researchers who ventured out into the community, giving flyers to women who appeared to meet the inclusion criteria (AA, overweight, and over 18 years old), and they explained the study, the purpose of the study, and the confidentiality of the study to prospective participants. To alleviate this limitation in this study, I spent about $2 \mathrm{hr}$ at each location handing out flyers to prospective participants, explaining the purpose of the research study in a sensitive manner including the confidentiality of the study. I was culturally sensitive, empathic, and excited when explaining the research study to prospective participants I changed the location for recruitment and placement of flyers to include locations which were more private and serviced predominately AA women on the Southside of Chicago.

Biases existed in this study that could alter the findings, such as (a) moderator bias, (b) sensitivity bias, (c) social acceptability bias, (d) mood bias, (e) dominant respondent bias, and (f) consistency bias (Doody, Slevin, \& Taggart, 2013; Drury, Chiang, Esterhuizen, Freshwater, \& Taylor, 2014; Gill, Stewart, Treasure, \& Chadwick, 2008; Nagle \& Williams, n.d.; Pannucci \& Wilkins, 2010). In this study, there were no moderator or sensitivity biases during the focus group interview sessions. I was cognizant of eliminating these two biases by establishing rapport with each participant and ensuring that participants were comfortable in the focus group setting. As recommended by researchers, I refrained from making a negative facial expression or negative gestures during interview sessions (Drury et al., 2014; Gill et al., 2008; Nagle \& Williams, n.d.; Pannucci \& Wilkins, 2010). Additionally, I always spoke clearly to participants, allowing them to be open and honest while discussing their opinions and perceptions. Within every focus group interview session, there was one participant who tended to dominate the group discussion. This is referred to as dominant respondent bias. When this occurred, I invited other participants in the focus group interview session to share their thoughts and feelings. At times, participants would respond to questions similar to other participants. When these incidents occurred, I used probes to illicit a true response from the participant. For example, when a participant repeated the same response as another participant, I probed the participant by saying, "OK, your opinions are important, please explain more." There was no evidence of sensitivity bias, social acceptability bias, or mood bias observed during focus group sessions.

\section{Conclusion}

This research provided the factors that were needed to design an intervention that would motivate obese AA women to practice healthy soul food preparation. In this study, the perceptions of obese AA women regarding altering traditional soul food preparation were taste, family values, and consequences. Participants perceived that to maintain healthier new eating behaviors for themselves and their family, soul foods prepared in a healthy manner must taste good, healthy recipes must be available, healthy ingredients must be inexpensive and accessible, training must be provided for how to substitute various herbs and spices, and food must not be wasted. Barriers identified by obese AA women that could limit participation in an intervention designed to develop healthier eating habits were ignorance and laziness, transportation issues, lack of motivation, lack of education, lack of time, no incentives, and bad reviews. 
The AA women who prepare and consume traditional soul food do not know how to prepare soul food in any other way except the way they were taught by their parents and grandparents. According to the perceptions and beliefs of obese AA women, if traditional soul food can be prepared in a healthy manner and it tastes good, they would be willing to alter the way they prepare traditional soul food. The obese AA women in this study believed that if they prepared soul food in a healthy manner, they would experience improved health and reduced chronic illnesses associated with eating foods high in calories, fats, and sugars.

The results from this article can be disseminated among Hispanics, non-Hispanic Blacks, and nonHispanic Whites to inform the community at large how they can address obesity among all populations who prepare and consume high-calorie soul food. Furthermore, this article will help to eliminate health disparities among the AA population using culturally specific interventions to decrease mortality and morbidity among this population. One way to do this is by teaching AA women how to prepare healthy soul food. The healthy soul food intervention will be interactive in that AA women would physically prepare and taste healthy soul food dishes. Healthy soul food recipes and samples of herbs and spices would be given to participants along with flyers explaining how to access healthy soul food ingredients. To further advocate and campaign for positive social change, community leaders, social service agencies, health care providers, and clinicians are encouraged to create community initiatives and community support systems to collectively eradicate the obesity epidemic.

\section{References}

American Medical Association. (2013). The truth about obesity. Retrieved from http://www.amassn.org/ama/pub/news/news/2013/2013-06-18-new-ama-policies-annual-meeting.page

Amirrood, M. M., Taghdisi, M. H., Shidfar, F., \& Gohari, M. R. (2014). The impact of training on women's capabilities in modifying their obesity- related dietary behaviors: Applying familycentered empowerment model. Journal of Research in Health Sciences, 14, 76-81. Retrieved from http://jrhs.umsha.ac.ir/index.php/JRHS/article/view/1062/

Beagan, B. L., \& Chapman, G. E. (2012). Meanings of food, eating and health among African Nova Scotians: "Certain things aren't meant for Black folk." Ethnicity \& Health, 17, 513-529. doi:10.1080/13557858.2012.661844

Becker, M. H., Maiman, L. A., Kirscht, J. P., Haefner, D. P, \& Drachman, R. H. (1977). The health belief model and prediction of dietary compliance: A field experiment. Journal of Health and Social Behavior, 18, 348-366. doi:10.2307/2955344

Belle, G. (2009). Can the African-American diet be made healthier without giving up culture? Retrieved from https://www.york.cuny.edu/academics/writing-program/the-york-scholar1/volume-5.2-spring-2009/can-the-african-american-diet-be-made-healthier-without-givingup-culture

Boh, B., Lemmens, L. M., Jansen, A., Nederkoorn, C., Kerkhofs, V., Spanakis, G., ... Roefs, A. (2016). An ecological momentary intervention for weight loss and healthy eating via Smartphone and Internet: Study protocol for a randomised controlled trial. Trials, 17, 1-12. doi:10.1186/s13063-016-1280-x

Bower, K. M., Thorpe, R. J., Yenokyan, G., McGinty, E. E., Dubay, L., \& Gaskin, D. J. (2015). Racial residential segregation and disparities in obesity among women. Journal of Urban Health: Bulletin of the New York Academy of Medicine, 92, 843-852. doi:10.1007/s11524-015-9974-z 
Bratanova, B., Loughnan, S., Klein, O., Claassen, A., \& Wood, R. (2016). Poverty, inequality, and increased consumption of high calorie food: Experimental evidence for a causal link. Appetite, 100, 162-171. doi:10.1016/j.appet.2016.01.028

Broady, K., \& Meeks, A. (2015). Obesity and social inequality in America. Review of Black Political Economy, 42, 201-209. doi:10.1007/s12114-014-9202-1

Bronikowski, M., Bronikowska, M., Pluta, B., Maciaszek, J., Tomczak, M., \& Glapa, A. (2016). Positive impact on physical activity and health behaviour changes of a 15-week family focused intervention program: "Juniors for seniors." BioMed Research International, 5489348. doi:10.1155/2016/5489348

Chang, M., Nitzke, S., Brown, R., Egan, J. B., Bendekgey, C. M., \& Buist, D. (2017). Recruitment challenges and enrollment observations from a community based intervention (Mothers in Motion) for low-income overweight and obese women. Contemporary Clinical Trials Communications, 5, 26-33. doi:10.1016/j.conctc.2016.11.004

Chen, G. M., Williams, S., Hendrickson, N., \& Chen, L. (2012). Male mammies: A social-comparison perspective on how exaggeratedly overweight media portrayals of Madea, Rasputia, and Big Momma affect how Black women feel about themselves. Mass Communication \& Society, 15, 115-135. doi:10.1080/15205436.2011.569682

Cho, J. H., Jae, S. Y., Choo, I. H., \& Choo, J. (2014). Health-promoting behaviour among women with abdominal obesity: A conceptual link to social support and perceived stress. Journal of Advanced Nursing, 70, 1381-1390. doi:10.1111/jan.12300

Cozier, Y. C., Yu, J., Coogan, P. F., Bethea, T. N., Rosenberg, L., \& Palmer, J. R. (2014). Racism, segregation, and risk of obesity in the Black women's health study. American Journal of Epidemiology, 179, 875-883. doi:10.1093/aje/kwu004

Davison, K. K., Jurkowski, J. M., Li, K., Kranz, S., \& Lawson, H. H. (2013). A childhood obesity intervention developed by families for families: Results from a pilot study. The International Journal of Behavioral Nutritional and Physical Activity, 10, 1-13. doi:10.1186/1479-5868-10-3

Doody, O., Slevin, E., \& Taggart, L. (2013). Preparing for and conducting focus groups in nursing research: Part 2. British Journal of Nursing, 22, 170-173. doi:10.12968/bjon.2013.22.3.170

Drury, V., Chiang, P. P., Esterhuizen, P., Freshwater, D., \& Taylor, B. (2014). Researchers' experiences of focus group dynamics in Singapore, Australia and the Netherlands: Troubling multicultural assumptions. Journal of Research in Nursing, 19, 460-474. doi:10.1177/1744987114546722

Fukawa, N. (2016). Priming effects on affective preference for healthy products over unhealthy products upon brand exposure. Social Marketing Quarterly, 22, 34-53. doi:10.1177/1524500415620154

Geller, J. S., Dube, E. T., Cruz, G. A., Stevens, J., \& Bench, K. K. (2015). Pediatric obesity empowerment model group medical visits (POEM-GMV) as treatment for pediatric obesity in an underserved community. Childhood Obesity, 11, 638-646. doi:10.1089/chi.2014.0163

Glanz, K., Rimer, B. K., \& Viswanath, K. (Eds.). (2008). Health behavior and health education: Theory, research, and practice (4th ed.). San Francisco, CA: Jossey-Bass. 
Gill, P., Stewart, K., Treasure, E., \& Chadwick, B. (2008). Methods of data collection in qualitative research: Interviews and focus groups. British Dental Journal, 204, 291-295.

doi:10.1038/bdj.2008.192

Hall, P. A. (2016). Executive-control processes in high-calorie food consumption. Current Directions in Psychological Science, 25, 91-98. doi:10.1177/0963721415625049

Huang, J., Huang, S., Li, R., Wang, L., Chen, Y., \& Tang, F. (2014). Effects of nutrition and exercise health behaviors on predicted risk of cardiovascular disease among workers with different body mass index levels. International Journal of Environmental Research and Public Health, 11, 4664-4675. doi:10.3390/ijerph110504664

James, D., Pobee, J. W., Oxjdine, D., Brown, L., \& Joshi, G. (2012). Using the health belief model to develop culturally appropriate weight-management materials for African American women. Journal of Academy of Nutrition and Dietetics, 112, 664-670. doi:10.1016/j.jand.2012.02.003

Jensen Wallach, J. (2014). How to eat to live: Black Nationalism and the post-1964 culinary turn. Retrieved from http://southernstudies.olemiss.edu/study-the-south/how-to-eat-to-live/

Jurkowski, J. M., Lawson, H. A., Green Mills, L. L., Wilner, P. G., \& Davison, K. K. (2014). The empowerment of low-income parents engaged in a childhood obesity intervention. Family \& Community Health: The Journal of Health Promotion \& Maintenance, 37, 104-118. doi:10.1097/FCH.0000000000000024

Kim, J., \& Zane, N. (2016). Help-seeking intentions among Asian American and White American students in psychological distress: Application of the health belief model. Cultural Diversity \& Ethnic Minority Psychology, 22, 311-321. doi:10.1037/cdp0000056

Lavalle, F., McGowan, L., Spence, M., Caraher, M., Raats, M. M., Hollywood, L. ... Dean, M. (2016). Barriers and facilitators to cooking from "scratch" using basic or raw ingredients: A qualitative interview study. Appetite, 107, 393-391. doi:10.1016/j.appet.2016.08.115

Lee, S. T., \& Lien, N. H. (2015). The influence of adult family members on children's fast food consumption: A health belief perspective. Journal of Communication in Healthcare, 8 , 185-196. doi:10.1179/1753807615Y.0000000017

Liamputtong, P. (2011). Focus group methodology: Principle and practice (1st ed.). Thousand Oaks, CA: Sage.

Li, Y., Robinson, L. E., Carter, W. M., \& Gupta, R. (2015). Childhood obesity and community food environments in Alabama's Black Belt region. Child: Care, Health and Development, 41, 668-676. doi:10.1111/cch.12204

Lopez, I. A., Boston, P. Q., Dutton, M., Jones, C. G., Mitchell, M. M., \& Vilme, H. (2014). Obesity literacy and culture among African American women in Florida. American Journal of Health Behavior, 38, 541-552. doi:10.5993/ajhb.38.4.7

Nagle, B., \& Williams, N. (n.d.). Methodology brief: Introduction to focus groups. Retrieved from http://www.mmgconnect.com/projects/userfiles/file/focusgroupbrief.pdf

Nederkoorn, C. (2014). Effects of sales promotions, weight status, and impulsivity on purchases in supermarket. Obesity, 22, E2-E5. doi:10.1002/oby.20521

Pannucci, C. J., \& Wilkins, E. G. (2010). Identifying and avoiding bias in research. Plastic and Reconstructive Surgery, 126, 619-625. doi:10.1097/PRS.0b013e3181de24bc 
Patton, M. (1990). Qualitative evaluation and research methods (pp. 169-186). Beverly Hills, CA: Sage.

Petrick, G. M. (2011). Hog and hominy: Soul food from Africa to America. Journal of Social History, 45, 326-328. doi:10.1093/jsh/shr041

Polsky, J. Y., Moineddin, R., Dunn, J. R., Glazier, R. H., \& Booth, G. L. (2016). Absolute and relative densities of fast-food versus other restaurants in relation to weight status: Does restaurant mix matter? Preventive Medicine, 82, 28-34. doi:10.1016/j.ypmed.2015.11.008

Rahmati-Najarkolaei, F., Tavafian, S. S., Fesharaki, M. G., \& Jafari, M. R. (2015). Factors predicting nutrition and physical activity behaviors due to cardiovascular disease in Tehran University students: Application of health belief model. Iranian Red Crescent Medical Journal, 17, 1-6. doi:10.5812/ircmj.18879

Rashid, J. R., Leath, B. A., Truman, B. I., Atkinson, D. D., Gary, L. C., \& Manian, N. (2017). Translating comparative effectiveness research into practice: Effects of interventions on lifestyle, medication adherence, and self-care for Type 2 diabetes, hypertension, and obesity among Black, Hispanic, and Asian residents of Chicago and Houston, 2010 to 2013. Journal of Public Health Management \& Practice, 23, 468-476. doi:10.1097/PHH.0000000000000525

Reed, J. R., Yates, B. C., Houfek, J., Briner, W., Schmid, K. K., \& Pullen, C. (2016). A review of barriers to healthy eating in rural and urban adults. Online Journal of Rural Nursing \& Health Care, 16, 122-153. doi:10.14574/ojrnhc.v16il.379

Rodgers, R. F., Franko, D. L., Shiyko, M., Intille, S., Wilson, K., O'Carroll, D., ... Shoemaker, H. (2016). Exploring healthy eating among ethnic minority students using mobile technology: Feasibility and adherence. Health Informatics Journal, 22, 440-450. doi:10.1177/1460458214565950

Schulz, P. J. (2014). Social influences of health literacy and patient empowerment. Patient Education and Counseling, 94, 2-3. doi:10.1016/j.pec.2013.11.002

Schulz, P. J., \& Nakamoto, K. (2013). Health literacy and patient empowerment in health communication: The importance of separating conjoined twins. Patient Education and Counseling, 90, 4-11. doi:10.1016/j.pec.2012.09.006

Sharp, L. K., Fitzgibbon, M. L., \& Schiffer, L. (2008). Recruitment of obese Black women into a physical activity and nutrition intervention trial. Journal of Physical Activity and Health, 5, 870-881. Retrieved from http://fitnessforlife.org/AcuCustom/Sitename/Documents/DocumentItem/16310.pdf

Sheean, P., Liang, H., Schiffer, L., Arroyo, C., Troy, K., \& Stolley, M. (2016). Assessing the prevalence of compromised bone health among overweight and obese African-American breast cancer survivors: A case-control study. Journal of Cancer Survivorship, 10, 21-30. doi:10.1007/s11764-015-0448-9

Shu-Fang, S., Chieh-Hsing, L., Li-Ling, L., Osborne, R. H., Shih, S., Liu, C., \& Liao, L. (2016). Health literacy and the determinants of obesity: A population-based survey of sixth grade school children in Taiwan. Biological Medicine Central Public Health, 16, 1-8. doi:10.1186/s12889016-2879-2

Spooner, S. (2015). What the slaves brought: Africa's great gift to American cuisine-and the remarkable history of some humble veggies. Retrieved from http://mgafrica.com/article/201511-02-african-food-america 
Thompson, C. (2015). Neoliberalism, soul food, and the weight of Black women. Feminist Media Studies, 15, 794-812. doi:10.1080/14680777.2014.1003390

U.S. Department of Health and Human Services, Office of Minority Health. (2017). Obesity and African American. Retrieved from https://minorityhealth.hhs.gov/omh/browse.aspx?lvl=4\&lvlid=25

Waters, S., Diggins, A., Woods-Giscombe, C., \& Waters, S. (2015). The association of perceived stress, contextualized stress, and emotional eating with body mass index in college-aged Black women. Eating Behaviors, 19, 188-192. doi:10.1016/j.eatbeh.2015.09.006

Wilson, S. M., \& Sato, A. F. (2014). Stress and paediatric obesity: What we know and where to go. Stress and Health: Journal of the International Society for the Investigation of Stress, 30, 91-102. doi:10.1002/smi.2501

Yates, B. C., Norman, J., Meza, J., Krogstrand, K. S., Harrington, S., Shurmur, S., ... Schumacher, K. (2015). Effects of partners together in health intervention on physical activity and healthy eating behaviors: A pilot study. Journal of Cardiovascular Nursing, 30, 109-120. doi:10.1097/JCN.0000000000000127

Zylke, J. W. \& Bauchner, H. (2016). The unrelenting challenge of obesity. Journal of American Medicine, 315, 2277-2278. doi:10.100/jama.2016.6190

The Journal of Social, Behavioral, and Health Sciences is an open-access, peer-reviewed, online interdisciplinary journal focusing on research findings that address contemporary national and international issues. Its objectives are to (a) encourage dialogue between scholars and practitioners in the social, behavioral, and health sciences that fosters the integration of research with practice; (b) promote innovative models of interdisciplinary collaboration among the social, behavioral, and health sciences that address complex social problems; and (c) inform the relationship between practice and research in the social, behavioral, and health sciences.

Walden University Publishing: http://www.publishing.waldenu.edu 